\title{
Cerebral tumour presenting with hyperventilation
}

\author{
L. S. LANGE AND G. LASZLO \\ From the Department of Neurology and the Metabolic Unit, \\ St. Mary's Hospital, Paddington, London
}

Overbreathing caused by pontine lesions may occur as a terminal event in unconscious patients. A case of malignant cerebral reticulosis infiltrating the brain-stem is described where overbreathing was a presenting feature and persisted for 41 days until the patient's death. A search of the literature has failed to reveal a similar case.

\section{CASE HISTORY}

An unmarried man aged 51 had suffered from chronic bilateral anterior and posterior uveitis of unknown aetiology for seven years. Because the condition was poorly controlled with atropine and local steroids, oral Prednisone, $60 \mathrm{mg}$. daily, was added to the treatment and the dose was progressively reduced over three months to $35 \mathrm{mg}$. daily. Supplementary protein and potassium were given and the calorie intake restricted. In spite of this treatment his eyesight deteriorated gradually. He was, however, noted to be cheerful and alert throughout this period, spent as an in-patient at Moorfields Hospital.

Two months later he was referred to the Metabolic Unit at St. Mary's Hospital for advice to control the sideeffects of steroid administration. During the interview it was noted that the patient was overbreathing. He was aware of this but had not complained of it. He did not feel short of breath. He complained of difficulty in concentrating and his sister noticed that he had become much quieter during the previous week and was given to vacant staring.

Examination revealed a plethoric man with truncal obesity, moderately wasted limbs but no cutaneous striae. The temperature was $98.4^{\circ} \mathrm{F}$ and the skin was hot and dry. The respiratory rate was 32 per minute. His chest expansion was normal ( 2 in.) when performed voluntarily but the involuntary hyperventilation was performed predominantly by the diaphragm. Examination of the chest was normal apart from a few scattered rhonchi. The pulse was regular at 120 per minute, and blood pressure $180 / 100 \mathrm{~mm}$. Hg. The apex beat was not displaced. An apical gallop rhythm was heard intermittently.

There was no lymph node or thyroid enlargement.

$\mathrm{He}$ was conscious and fully orientated but responded slowly and concentrated poorly. He was unable to perform elementary calculations and his memory was poor. There was no disturbance of mood apart from anxiety at his poor performance.
His pupils were dilated by mydriatics but circular. Opacity of the media prevented visualization of the fundi. Eye movements were full and there was no nystagmus. The other cranial nerves functioned normally. Trousseau's and Chvostek's signs were not elicited. A continuous moderately coarse tremor was present in the hands at rest which could be aggravated by movement or by anxiety to involve the whole body. There was some generalized weakness commensurate with the muscle wasting. Tone was normal. There was some clumsiness of repetitive movements, the deep reflexes were symmetrically brisk, both plantar responses were flexor and sensation was intact.

INVESTIGATIONS An arterial sample on admission showed $p \mathrm{H} 7 \cdot 58 ; \mathrm{PCO}_{2} 12 \mathrm{~mm}$. $\mathrm{Hg}$. ; standard bicarbonate $19.0 \mathrm{mEq}$./l.; plasma total $\mathrm{CO}_{2} 14.6 \mathrm{mMoles} / \mathrm{l}$; ; buffer base $43.2 \mathrm{mEq}$./1.; base excess $5.9 \mathrm{mEq}$./1.; oxygen saturation $99 \%$.

Venous samples gave: sodium $144 \mathrm{mEq} . / 1 . ;$ potassium $2.9 \mathrm{mEq}$./1.; chloride $104 \mathrm{mEq}$./1.; calcium $9.5 \mathrm{mg}$./100 ml.; inorganic phosphorus $3.0 \mathrm{mg} . / 100 \mathrm{ml}$; magnesium 1.4 mg./100 ml.; urea $53 \mathrm{mg} . / 100 \mathrm{ml}$.; glucose $122 \mathrm{mg} . / 100$ ml.; total protein $6.1 \mathrm{~g} . / 100 \mathrm{ml}$; albumin $4.3 \mathrm{~g} . / 100 \mathrm{ml}$; globulin $2.0 \mathrm{~g} . / 100 \mathrm{ml}$.; electrophoresis normal; bilirubin normal; thymol turbidity normal; serum glutamicoxaloacetic transaminase (SGOT) 21 units $/ \mathrm{ml}$.; serum glutamic-pyruvic transaminase (SGPT) 18 units $/ \mathrm{ml}$; haemoglobin 15.6 g. $/ 100 \mathrm{ml}$; ; packed cell volume $44 \%$; mean corpuscular haemoglobin concentration $35 \%$; white cell count 15,000 per c.mm. (neutrophils 13,200 per c.mm. lymphocytes 1,500 per c.mm.; monocytes 300 per c.mm.); E.S.R. $12 \mathrm{~mm}$. in one hour (Westergren). Blood culture was sterile.

Urine showed no deposit and was sterile on culture. The ferric chloride test for salicylates was negative.

Electrocardiograph showed flattening of $t$ waves in all leads partly reversed with a fall of blood $p \mathrm{H}$.

Radiographs of the chest, skull, and lumbar spine were normal.

Electroencephalograms (1) at blood $p \mathrm{H} 7.55$ showed a marked generalized abnormality with some evidence of a local disturbance over the left hemisphere; (2) at blood $p \mathrm{H} 7.49$ after morphine, generalized abnormality with no localization.

The hyperventilation was present even during sleep, and proved resistant to sodium phenobarbitone $(180 \mathrm{mg}$. by intramuscular injection), chloral hydrate ( $2 \mathrm{~g}$. orally), and chlorpromazine ( $50 \mathrm{mg}$. by intramuscular injection). 
The respiratory rate varied between 24 and 46 per minute but always fell to below 30 per minute after $10 \mathrm{mg}$. to $15 \mathrm{mg}$. of morphine. Nine arterial $p \mathrm{H}$ readings in 18 days lay between $7 \cdot 49$ and $7 \cdot 60$, and one at $7 \cdot 43$. The partial pressures of $\mathrm{CO}_{2}$ in the blood $\left(\mathrm{PcO}_{2}\right)$ were between 24 $\mathrm{mm}$. $\mathrm{Hg}$ and $12 \mathrm{~mm}$. $\mathrm{Hg}$, never rising to normal even after morphine. The standard bicarbonate varied only from $19.5 \mathrm{mEq}$./litre to $22.5 \mathrm{mEq}$./litre. One hundred per cent oxygen failed to affect the respiratory rate. $\mathrm{CO}_{2}$-enriched air was not tried as Plum and Swanson (1959) have shown this to aggravate central neurogenic hyperventilation.

The tachycardia and intermittent gallop rhythm suggested left ventricular failure but mersalyl and aminophylline, which were given once, had no therapeutic effect.

It was thought possible that intoxication with atropine or corticosteroids might be causing this unusual clinical picture and these drugs were withdrawn, with suitable precautions, in turn. This produced no improvement and it was then thought that the likeliest diagnosis was that of diffuse infiltration or arteriosclerotic degeneration of the respiratory centres in the pons.

The demonstrated potassium, and presumptive sodium, deficits were treated by oral supplements. A minimum daily intake of $100 \mathrm{mEq}$. of these ions was required to ensure the excretion of an alkaline urine.

In the meantime the patient became increasingly disorientated and after 12 days neurological localizing signs appeared. He remained conscious but became aphasic and dyspraxic and developed a left-sided grasp reflex. Later a right hemiparesis and homonymous hemianopia appeared with persistent ocular deviation to the right. Lumbar puncture, air encephalography (A.E.G.), and left carotid arteriography were performed with the following results:

The cerebrospinal fluid contained protein $92 \mathrm{mg} . / 100$ $\mathrm{ml}$. and glucose $75 \mathrm{mg} . / 100 \mathrm{ml}$., the Lange curve was 0000000 , the Pandy test was positive, cells were 2 per c.mm., the Wassermann reaction was negative, and culture sterile.

A moderate amount of air entered the ventricular system and showed a gross shift of the septum and third ventricle to the right of the mid-line.

A left carotid arteriogram showed that the anterior cerebral artery was displaced well to the right of the midline. In the lateral view the middle cerebral artery was displaced upwards and its distal branches stretched. The appearances suggested a large left temporal tumour extending deeply.

After the A.E.G. the patient developed acute pulmonary oedema and required emergency tracheostomy. On the next day, after the cerebral angiogram was obtained, he was transferred to the Maida Vale Hospital under the care of Mr. Valentine Logue.

After ventriculography, which showed the bulk of the lesion to be temporo-occipital, a biopsy showed the brain to be infiltrated with foci of small irregular round cells thought to be neoplastic.

The patient's condition remained unaltered and he continued to hyperventilate until he suddenly deteriorated and died on 26 April 1963, 41 days after the hyperventilation was first noted.

\section{POST-MORTEM REPORT}

The brain weighed $1,480 \mathrm{~g}$. The left cerebral hemisphere was greatly swollen; there was uncal grooving and cingulate herniation on this side. In the left occipital cortex and white matter there was pale granular tumour $O$ tissue of indefinite edge occupying an area about $3.5 \times \underset{\infty}{\infty}$ $3.0 \mathrm{~cm}$. infiltrating the meninges medially and extending $\stackrel{\rho}{\stackrel{5}{ }}$, forward to the posterior margin of the lateral ventricle. In the mid-brain and upper pons the periaqueductal grey matter appeared swollen and 'blurred'. The aqueduct was slightly displaced toward the right. There was no evidences? of coning through the foramen magnum.

Histologically the occipital tumour fell into the groups $\frac{\bar{C}}{\sigma}$ of malignant cerebral reticulosis or 'microglioma'. The $\overline{\bar{c}}$ features of these uncommon lesions were described by $\overrightarrow{\mathbb{D}}$. Russell, Marshall, and Smith (1948) and were recently $\varrho$ reviewed by Miller and Ramsden (1963), who proposed a 'spectrum' to include the various varieties: this tumour $\vec{\circ}$ could be placed at the sarcomatous end. It consisted of $?$ thick cuffs of cells surrounding blood vessels, whose $\overrightarrow{\vec{\omega}}$ nuclei were vesicular and contained prominent nucleoli, $\omega$ surrounded by a small hazy rim of cytoplasm. Mitotic figures were often seen. There was marked astrocytic proliferation around the tumour deposits.

In the mid-pons, upper pons, and mid-brain there was $\infty$ very widespread perivascular infiltration by tumour cel which extended through the peri-aqueductal grey matte inferior colliculi, nuclei substantia nigra, basis peduncuh, 0 and between the fibre tracts of the pons reaching the brachia conjunctiva and pontis. There was a thin menity geal coating of cells.

The tumour did not involve the medulla oblongata 옹읃 spinal cord.

There were several small pale grey foci (larges: $\vec{c}$ $2 \times 1 \times 1 \mathrm{~cm}$.) of abnormal tissue in the liver (weigh $1,545 \mathrm{~g}$.), but there was no enlargement of any group of lymph nodes or of the spleen $(60 \mathrm{~g}$.). The lungs (right 580 g., left 590 g.) were congested and oedematous with bilateral basal pneumonia and mucus bronchitis; after $\bar{\partial}$ fixation, parallel slices at less than $0.5 \mathrm{~cm}$. intervals were made and no tumour tissue could be identified. $\stackrel{\circ}{\Phi}$ The heart (394 g.) showed no abnormality: atheroma of coronary arteries and main blood vessels was moderate. $\overrightarrow{\bar{O}}$

The deposits in the liver were of primitive lymphoid 3 cells similar to those forming the perivascular cuffs of the cerebral tumour. Here the proliferation was in solid sheets; mitotic figures were numerous; many fine reticulin fibres ran between individual cells. In the lumbar vertebral marrow groups of similar cells were present but all other? organs were tumour-free both to naked-eye and histological examination.

The conclusion was that this was a primary malignant $\frac{\rho}{2}$ cerebral reticulosis: focal proliferation of primitive cells 3 in other situations containing reticular tissue has been $ᄋ$ described in several of the reports of this condition.

\section{DISCUSSION}

The arterial blood chemistry on admission indicated the presence of a respiratory alkalosis with slight renal compensation. 
By exclusion, the definitive diagnosis of central neurogenic hyperventilation was reached after a few days. Plum and Swanson (1959) discuss the difficulty in excluding pulmonary oedema in which a normal oxygen saturation and low $\mathrm{PcO}_{2}$ are often found. Our patient had no cardiac enlargement and the ventilatory rate was unaffected by oxygen, by his position in the bed, and by treatment with mersalyl and aminophylline. Moreover, the oxygen saturation of his blood while breathing air was as high as $99 \%$.

Plum and Brown (1963) suggest that central neurogenic hyperventilation occurs when a lesion in the medial pontine tegmentum prevents descending inhibitory impulses reaching the medullary respiratory centres. In our patient the pontine lesion was so extensive as to preclude speculation about the exact anatomical localization of the respiratory pathways in the brain-stem. It was of great interest to us that this patient's earliest signs were of hyperventilation while he was still fully conscious without any other recognizable neurological deficit.

\section{SUMMARY}

A patient is described who presented with respiratory alkalosis caused by a cerebral tumour invading the brain-stem.

We are indebted to Mr. A. G. Cross, Mr. Valentine Logue, and Dr. Victor Wynn for permission to publish this case report. We should also like to thank Dr. Robin Barnard for the post-mortem report.

\section{REFERENCES}

Miller, A. A., and Ramsden, F. (1963). Primary reticulosis of the central nervous system-'microgliomatosis'. Acta neurochir. (Wien), 11, 439-478.

Plum, F., and Brown, H. W. (1963). The effect of respiration of central nervous system disease. Ann. N.Y. Acad. Sci., 109, 915-31.

- and Swanson, A. G. (1959). Central neurogenic hyperventilation in man. Arch. Neurol. Psychiat. (Chic.), 81, 535-49.

Russell, Dorothy S., Marshall, A. H. E., and Smith, F. B. (1948). Microgliomatosis. A form of reticulosis affecting the brain. Brain, 71, 1-15. 